\title{
Assessment of a prototype implantable cardioverter for ventricular tachycardia \\ Relation between synchronisation of sensing and origin of the tachycardia
}

\author{
M S PERELMAN, E ROWLAND, D M KRIKLER \\ From the Division of Cardiovascular Disease, Royal Postgraduate Medical School, London
}

SUMMARY The feasibility of internal cardioversion for ventricular tachycardia using a prototype of an implantable cardioverter which delivers a low energy discharge via an intracardiac lead and its acceptability to the patient were studied. The cardioverting discharge was synchronised to the apical right ventricular electrogram. In 29 episodes of ventricular tachycardia ( $R R$ interval 250-700 ms) the apical electrogram was reliably sensed. The interval from the onset of the QRS complex to the marker of sensing of the electrogram was significantly greater in the 15 episodes arising from the left ventricle than in the 14 episodes arising from the right ventricle; in three cases of ventricular tachycardia arising from the left ventricle the interval exceeded $100 \mathrm{~ms}$. In all cases except one, however, sensing occurred within the first $80 \%$ of the QRS complex. In two episodes (RR interval 150 and $190 \mathrm{~ms}$-that is, less than the refractory period of the unit) sensing of the electrogram was unreliable. The unit successfully terminated 10 of 15 episodes of ventricular tachycardia using energies ranging between 0.01 and $1.0 \mathrm{~J}$, but 19 of the 23 discharges delivered to conscious patients caused varying degrees of discomfort. Sensing within $100 \mathrm{~ms}$ of the onset of the QRS complex ( $-20 \%$ to $83 \%$ of QRS) permitted effective and safe termination of ventricular tachycardia. Although there was neither acceleration of tachycardia nor ventricular fibrillation, subthreshold discharges advanced the next local ventricular electrogram in seven instances. An external low energy cardioverter connected to an intracardiac lead is a useful alternative to repeated external direct current shocks.

Although drugs remain the mainstay in the treatment and prevention of recurrent ventricular tachycardia, there is a group of patients in whom antiarrhythmic drugs are ineffective or in whom the negative inotropism precludes their use. Electrical methods, including pacemakers, may be used but usually require the presence of experienced personnel and often admission to hospital. External direct current cardioversion/ defibrillation delivered across the thorax is the most effective method but requires a high energy source. Low energies $(<2.5 \mathrm{~J})$ delivered directly to the

Requests for reprints to Dr M S Perelman, Division of Cardiovascular Disease, Royal Postgraduate Medical School, Hammersmith Hospital, Ducane Road, London W12 0HS.

Accepted for publication 7 June 1984 myocardium via a transvenous lead terminate ventricular tachycardia in over $83 \%$ of cases. ${ }^{1-3}$ Previous studies have used a modified external defibrillator as the energy source, 12 whereas in this study we used a prototype of a fully implantable cardioverter (Medtronic 2342, refractory period $205 \mathrm{~ms}$ ). With this unit the apical right ventricular electrogram was used to synchronise the delivery of the discharges.

Initially, we examined the synchronisation of sensing, by the cardioverter, to the apical right ventricular electrogram and to the QRS complex during episodes of ventricular tachycardia. Later the prototype cardioverter was used to terminate episodes of ventricular tachycardia, whether occurring spontaneously or induced during routine diagnostic electrophysiological studies. 


\section{Patients and methods}

Thirty one separate episodes of ventricular tachycardia previously recorded during electrophysiological studies were played back using a Racal Thermionic 14 channel tape recorder (frequency response DC to $400 \mathrm{~Hz}$ ). The surface electrocardiogram (leads I, III, V1, and V6) together with the apical right ventricular electrogram were displayed on a 12 channel electrocardiograph (Siemens-Elema mingograph). The apical right ventricular electrogram, after being attenuated to approximately $5 \mathrm{mV}$, was simultaneously delivered to the sensing channel of the cardioverter. The sensitivity of sensing by the cardioverter was adjusted (range $0.5-10 \mathrm{mV}$ ) so that each ventricular complex was correctly sensed. A marker of sensing, generated by the cardioverter, was displayed together with the original electrical signals at a paper speed of $100 \mathrm{~mm} / \mathrm{s}$ (Fig. 1); this marker indicates the time at which a cardioverting discharge would be delivered had the unit been activated. The intervals from the onset of the QRS complex and from the onset of the apical right ventricular electrogram to the marker of sensing were calculated over 20 consecutive complexes selected at random from each episode of ventricular tachycardia.

The right or left ventricular origin of the tachycardias was determined by endocardial mapping performed at the time of the original electrophysiological study.

\section{STUDY POPULATION}

Nine patients with recurrent sustained ventricular tachycardia resistant to drug treatment were investigated after informed written consent had been obtained; the study was approved by the research and ethics committee of our institution. All patients had been admitted for routine diagnostic electrophysiological study; the Table shows the clinical data. Thirteen episodes of ventricular tachycardia were induced during electrophysiological study whereas two arose spontaneously. Six of the patients had required previous conventional external direct current cardioversion.

\section{TECHNIQUE}

A 9.5 F gauge cardioverting lead with four separate stainless steel electrodes arranged in two pairs, each electrode having a surface area of $1.25 \mathrm{~cm}^{2}$, was used. The two distal electrodes, at the tip of the lead, are separated by $5 \mathrm{~mm}$ and can be used as a conventional bipolar lead for pacing or sensing. When a discharge is delivered the distal pair of electrodes are linked as the active cathode; the proximal pair are permanently connected and act as the anode. The leads are made with three different distances between the proximal and distal pairs of electrodes: 100,125 , and $150 \mathrm{~mm}$; in most cases we used leads with a separation of 125 $\mathrm{mm}$ so that the proximal pair of electrodes was positioned in the high right atrium.

The cardioverting lead was inserted, under local anaesthesia, into one of the subclavian veins and advanced under $x$ ray screening to the right ventricle and positioned so that the tip lay at the apex of the right ventricle and the proximal electrodes were in the superior vena cava or high right atrium, usually the latter. The impedance and pacing threshold were measured before and after any discharges as a check against dislodgement. During the electrophysiological studies the stability of the electrode was confirmed by radiography. The apical right ventricular electrogram

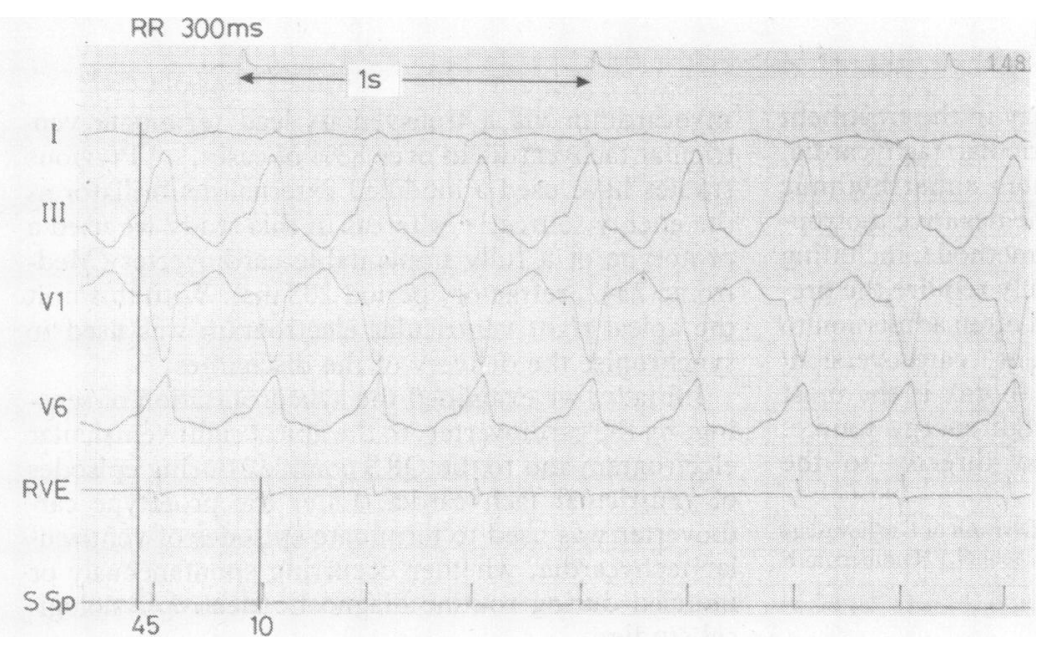

Fig. 1 Example of ventricular tachycardia originating from the right ventricle showing the surface electrocardiogram (leads $I, I I I, V 1$, and V6), the apical right ventricular electrogram (RVE), and the marker of sensing $(S S p)$. The time intervals (ms) between the onset of the RVE to the sensing marker, as well as the $Q R S$ onset to sensing marker, are indicated. 
Table 1 Patient data

\begin{tabular}{|c|c|c|c|c|c|c|c|c|c|c|}
\hline $\begin{array}{l}\text { Case } \\
\text { No }\end{array}$ & $\begin{array}{l}\text { e Age (yr) } \\
\text { and sex }\end{array}$ & Diagnosis & $\begin{array}{l}\text { Treatment } \\
\text { (mg/day) }\end{array}$ & $\begin{array}{l}\text { Origin of } \\
\text { tachycardia }\end{array}$ & $\begin{array}{l}R R \\
\text { interval } \\
\text { (ms) }\end{array}$ & $\begin{array}{l}\text { QRS } \\
\text { duration } \\
\text { (ms) }\end{array}$ & $\begin{array}{l}\text { Energy of } \\
\text { discharge } \\
(\mathcal{F})\end{array}$ & $\begin{array}{l}Q S \\
\text { interval } \\
(m s)\end{array}$ & Effect & Patients' reaction \\
\hline \multirow[t]{2}{*}{1} & \multirow[t]{2}{*}{$39 \mathrm{M}$} & \multirow[t]{2}{*}{ COCM } & & LV & 450 & 150 & 0.01 & 100 & NT & \multirow{2}{*}{$\begin{array}{l}\text { Severe abdominal pain; involuntary hip } \\
\text { flexion } \\
\text { Lead tip moved; moderate chest pain }\end{array}$} \\
\hline & & & (b) A 600 & LV & 460 & 160 & 0.01 & 100 & NT & \\
\hline 2 & $32 \mathrm{M}$ & $\mathrm{CHB}$ & (a) - & $\mathbf{R V}$ & 370 & 140 & 0.01 & -20 & NT & Moderate chest discomfort \\
\hline 3 & $55 \mathrm{M}$ & CAD & (a) PF 450 & LV & 600 & 200 & $\begin{array}{l}0.05 \\
0.10 \\
0.50 \\
0.75 \\
1.00 \\
2.00\end{array}$ & $\begin{array}{l}80 \\
80 \\
80 \\
80 \\
80 \\
80\end{array}$ & $\begin{array}{l}\text { NT } \\
\text { NT(A) } \\
\text { NT(A) } \\
\text { NT(A) } \\
\text { NT } \\
\text { NT }\end{array}$ & $\{$ Semiconscious \\
\hline \multirow[t]{2}{*}{4} & \multirow[t]{2}{*}{$44 \mathrm{~F}$} & \multirow[t]{2}{*}{$\begin{array}{l}\text { Idiopathic } \\
\text { VT }\end{array}$} & (a) - & RV & 300 & 210 & \multirow{2}{*}{$\begin{array}{l}0.25 \\
0.50 \\
1.0\end{array}$} & \multirow{2}{*}{$\begin{array}{l}40 \\
40 \\
20\end{array}$} & \multirow{2}{*}{$\begin{array}{l}\text { NTA(A) } \\
\text { NT(A) } \\
\text { T }\end{array}$} & \multirow{2}{*}{$\begin{array}{l}\text { Uncomfortable in the chest } \\
\text { More uncomfortable } \\
\text { Moderate pain in chest; brief run of } \\
\text { atrial fibrillation }\end{array}$} \\
\hline & & & (b) - & RV & 300 & 220 & & & & \\
\hline \multirow[t]{2}{*}{5} & \multirow[t]{2}{*}{$42 M$} & \multirow[t]{2}{*}{ CAD } & (a) $-\overline{P R} 2250$ & $\begin{array}{l}\text { LV } \\
\text { LV }\end{array}$ & $\begin{array}{l}270 \\
280\end{array}$ & $\begin{array}{l}200 \\
190\end{array}$ & \multirow{2}{*}{$\begin{array}{l}0.50 \\
0.25 \\
0.50 \\
1.00 \\
0.25 \\
0.50\end{array}$} & \multirow{2}{*}{$\begin{array}{r}100 \\
80 \\
80 \\
80 \\
100 \\
100\end{array}$} & \multirow{2}{*}{$\begin{array}{l}\text { T } \\
\text { NT } \\
\text { NT(A) } \\
\text { T } \\
\text { NT } \\
\text { T }\end{array}$} & $\begin{array}{l}\text { Moderate pain in the chest } \\
\text { Mild discomfort in the chest } \\
\text { "Easiest": returned to sinus rhythm }\end{array}$ \\
\hline & & & (c)PR3000 & LV & 380 & 120 & & & & Mild discomfort in the chest \\
\hline 6 & $58 \mathrm{M}$ & CAD & $\begin{array}{l}\text { (a) } \mathrm{D} 600 \\
\text { M } 100\end{array}$ & LV & 300 & 190 & 0.50 & $100^{-}$ & $\mathrm{T}$ & Painful in chest; involuntary hip spasm \\
\hline 7 & $88 \mathrm{~F}$ & CAD & $\begin{array}{l}\text { (a) D } 600 \\
\text { (b) D } 800 \\
\text { (c) D } 800\end{array}$ & $\begin{array}{l}\text { LV } \\
\text { LV } \\
\text { LV }\end{array}$ & $\begin{array}{l}420 \\
500 \\
460\end{array}$ & $\begin{array}{l}140 \\
150 \\
140\end{array}$ & $\begin{array}{l}0.25 \\
0.10 \\
0.01\end{array}$ & $\begin{array}{l}80 \\
80 \\
80\end{array}$ & $\begin{array}{l}\mathrm{T} \\
\mathbf{T} \\
\mathrm{T}\end{array}$ & $\begin{array}{l}\text { Mild chest discomfort } \\
\text { Mild chest discomfort } \\
\text { Mild chest discomfort }\end{array}$ \\
\hline 8 & $18 M$ & RVD & (a) A 400 & $\mathbf{R V}$ & 400 & 140 & $\begin{array}{l}0.25 \\
0.50\end{array}$ & $\begin{array}{l}80 \\
80\end{array}$ & $\underset{T}{\mathrm{NT}}(\mathrm{A})$ & $\begin{array}{l}\text { Painful } \\
\text { Very painful }\end{array}$ \\
\hline 9 & $72 \mathrm{~F}$ & MI & (a) A 100 & LV & 350 & 200 & $\begin{array}{l}0.01 \\
0.05 \\
0.1 \\
0.5 \\
1.0\end{array}$ & $\begin{array}{l}40 \\
40 \\
40 \\
40 \\
40\end{array}$ & $\left.\begin{array}{l}\text { NT } \\
\text { NT } \\
\text { NT } \\
\text { NT } \\
\text { T }\end{array}\right\}$ & $\begin{array}{l}\text { Patient response showed increasing } \\
\text { discomfort with the rise in energy }\end{array}$ \\
\hline
\end{tabular}

QS, interval from onset of QRS complex to marker of sensing; COCM, dilated cardiomyopathy; CHB, congenital heart block; CAD, coronary artery disease; MI, myocardial infarction; VT, ventricular tachycardia; RVD, right ventricular dysplasia; $A$, amiodarone; $P F$, propafenone; $\mathrm{PR}$, procainamide; D, disopyramide; M, metoprolol; LV, left ventricle; RV, right ventricle; NT, not terminated; T, terminated; (A), advancement of next ventricular complex or electrogram by a subthreshold discharge.

(recorded from the two distal electrodes of the cardioverting lead) was played directly into the cardioverter and the sensitivity adjusted $(0.5-10 \mathrm{mV})$ for accurate and reliable sensing.

The cardioverter is a battery powered unit which produces a monophasic, truncated, exponential discharge with a pulse duration of $5.5 \mathrm{~ms}$ when delivered into a load of $100 \Omega$. The energy delivered can be varied in 10 fixed steps between 0.01 and $5 \mathrm{~J}$. Once the unit is activated it automatically delivers a discharge, at a predetermined energy level, synchronised to the apical right ventricular electrogram.

For the electrophysiological study two or three more electrodes were inserted via the right femoral vein and positioned in the high right atrium and in the right ventricle. Ventricular tachycardia was induced either by incremental ventricular pacing or by pacing at a regular rate followed by single or double ventricu- lar stimuli.

When ventricular tachycardia occurred the accuracy of sensing was reconfirmed by examining the relation of the marker of sensing to the apical right ventricular electrogram and to the surface $Q R S$ as they were printed out. During ventricular tachycardia the electrogram was usually of lower amplitude than that seen in sinus rhythm $(80 \pm 35 \%)$. The cardioverter was then activated and discharges of increasing energy were delivered until the tachycardia was terminated or the patient experienced discomfort. If transvenous cardioversion failed an alternative procedure was used, either overdrive pacing or transthoracic direct current shock.

After each discharge the ventricular and atrial responses were noted and the patient's reactions recorded. Each patient was also questioned about any discomfort. 
Results

\section{RELATION OF SENSING TO THE QRS COMPLEX AND} TO THE ELECTROGRAM

Sixteen of the 31 episodes of ventricular.tachycardia arose from the right ventricle and 15 from the left ventricle. In 29 episodes of ventricular tachycardia (RR interval 250-700 ms) the apical right ventricular electrogram was consistently and reliably sensed but in two other episodes (RR interval 150 and $190 \mathrm{~ms}$ ) sensing was inconsistent. The interval from the onset of the QRS complex to the marker of sensing was significantly greater in those episodes arising from the left ventricle $(p<0.001)$, because the apical right ventricular electrogram occurred later in the QRS complex (Fig. 2). In three episodes arising in the left ventricle the interval from the onset of the QRS complex to the marker of sensing exceeded $100 \mathrm{~ms}$.

The two episodes in which malsensing occurred

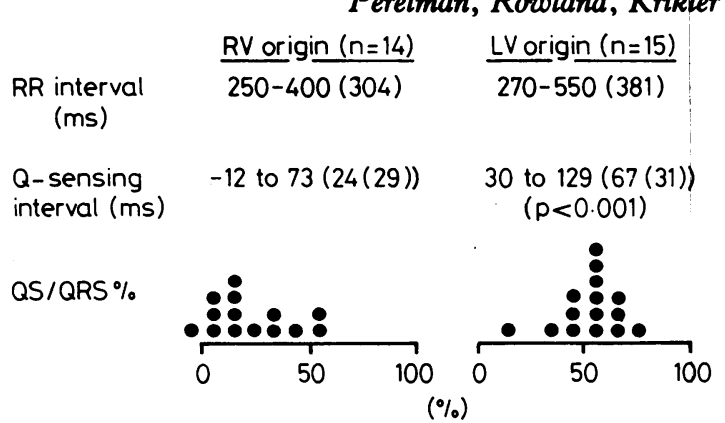

Fig. 2. $R R$ intervals (range and mean) and Q-sensing interval (range and mean $(S D)$ ) for 29 episodes of ventricular tachycardia. Also shown is the $Q S$ interval expressed as a percentage of the QRS duration for each patient.

both arose in the right ventricle and had $R R$ intervals of less than the refractory period of the unit. In one ( $R R$ interval $150 \mathrm{~ms}$ ) only alternate ventricular com-
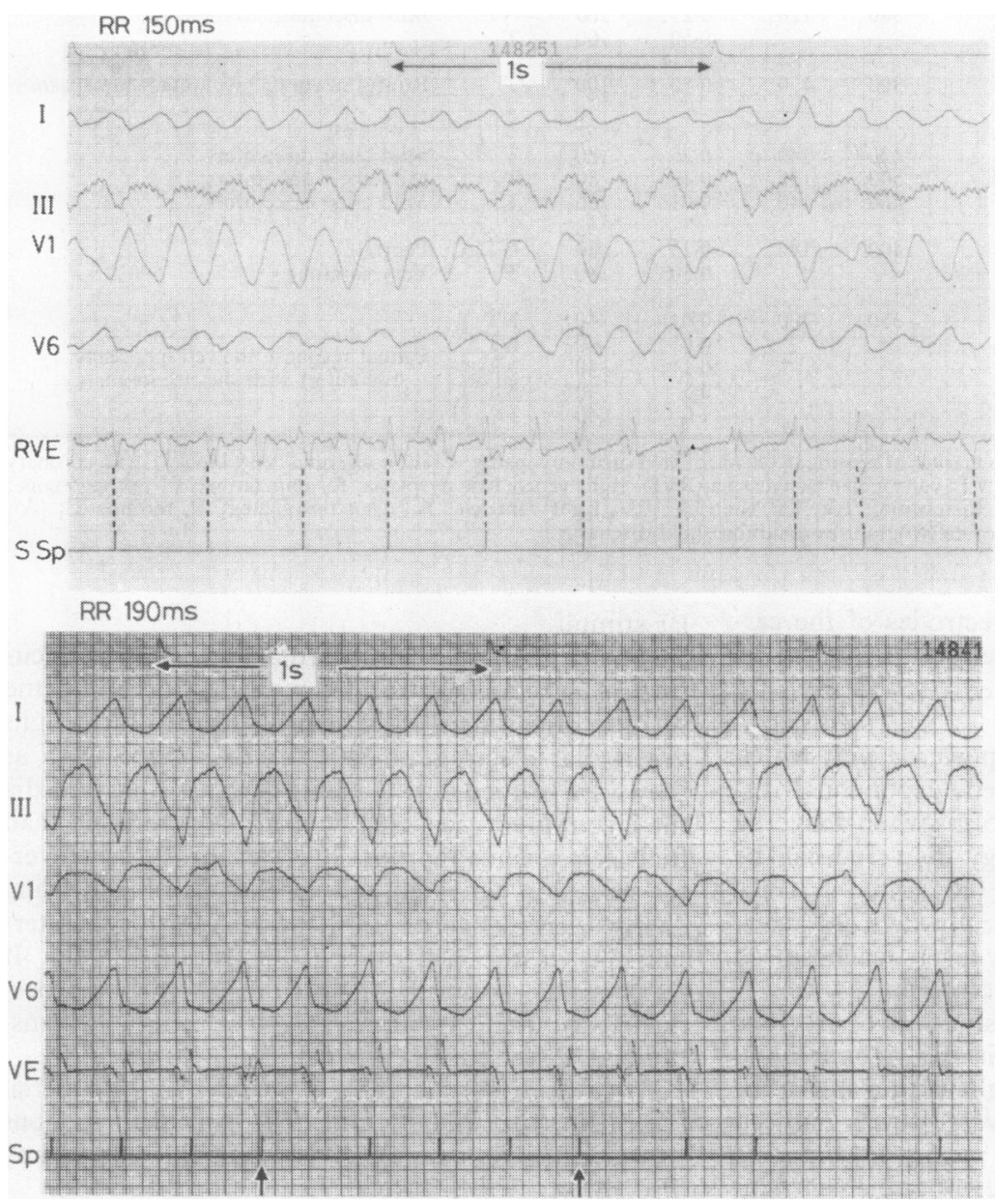

Fig. 3 Episode of ventricular tachycardia in which predominantly alternate complexes are sensed (same format as Fig. 1).

Fig. 4 Episode of ventricular tachycardia, with a cycle length just below the blanking period of the cardioverter. Occasional complexes are not sensed - the progressive delay between the onset of $Q R S$ and sensing marker results in the marker intermittently falling outside the $Q R S$ complex (arrows). Abbreviations as in Fig. 1. 
plexes were sensed with a variable delay between the electrogram and the marker of sensing (Fig. 3), although sensing always fell within the QRS complex. In the second ( $R R$ interval $190 \mathrm{~ms}$ ) the interval from the onset of the QRS complex to the marker of sensing progressively increased (Fig. 4) possibly because ventricular activity persisted beyond the blanking period of the unit $(205 \mathrm{~ms})$. During this episode of tachycardia the marker of sensing often fell outside the QRS complex (10-60 ms).

\section{EFFECT ON THE TACHYCARDIA}

Twenty nine discharges were delivered to nine patients during 15 separate episodes of ventricular tachycardia (Table), 11 of which arose from the left ventricle and four from the right ventricle (Fig. 5). In all episodes the apical right ventricular electrogram was sensed reliably and consistently. In three of the four episodes of tachycardia arising from the right ventricle sensing occurred within $40 \mathrm{~ms}$ of the onset of the QRS complex; in one case the electrogram preceded the QRS complex. In the fourth episode of right ventricular origin, occurring in a patient with right ventricular dysplasia, ${ }^{4}$ sensing did not occur until $80 \mathrm{~ms}$ after the onset of the QRS complex. In the episodes of tachycardia arising in the left ventricle the interval from the onset of the $\mathrm{QRS}$ complex to sensing varied from 80 to $100 \mathrm{~ms}$. In 10 of the 11 cases of left ventricular origin sensing occurred within the first $80 \%$ of the QRS complex; in one episode sensing accurred in the terminal $20 \%$ of the QRS complex

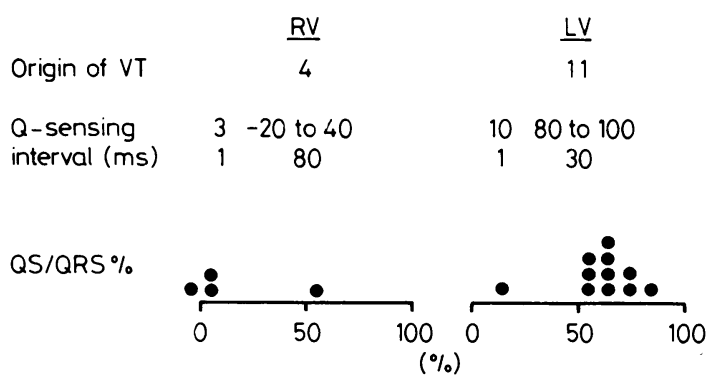

Fig. 5 Synchronisation of sensing in those episodes of ventricular tachycardia (VT) in which termination with low energy transvenous synchronised discharges was performed.

(QS/QRS 83\%), but this episode was terminated without acceleration or advancement.

Ten of the 15 episodes of ventricular tachycardia were successfully terminated by energies ranging between 0.01 and $1.0 \mathrm{~J}$ (Table). In six episodes the first energy level selected was successful. Although in four other episodes a series of discharges of increasing energy were required for termination (Fig. 6), the mean threshold for termination was $0.67 \mathrm{~J}$.

There were five episodes where transvenous cardioversion did not terminate the tachycardia (Table). In one the tachycardia terminated spontaneously after two subthreshold discharges. On three occasions the lowest energy setting $(0.01 \mathrm{~J})$ was associated with such severe discomfort or pain that higher energies

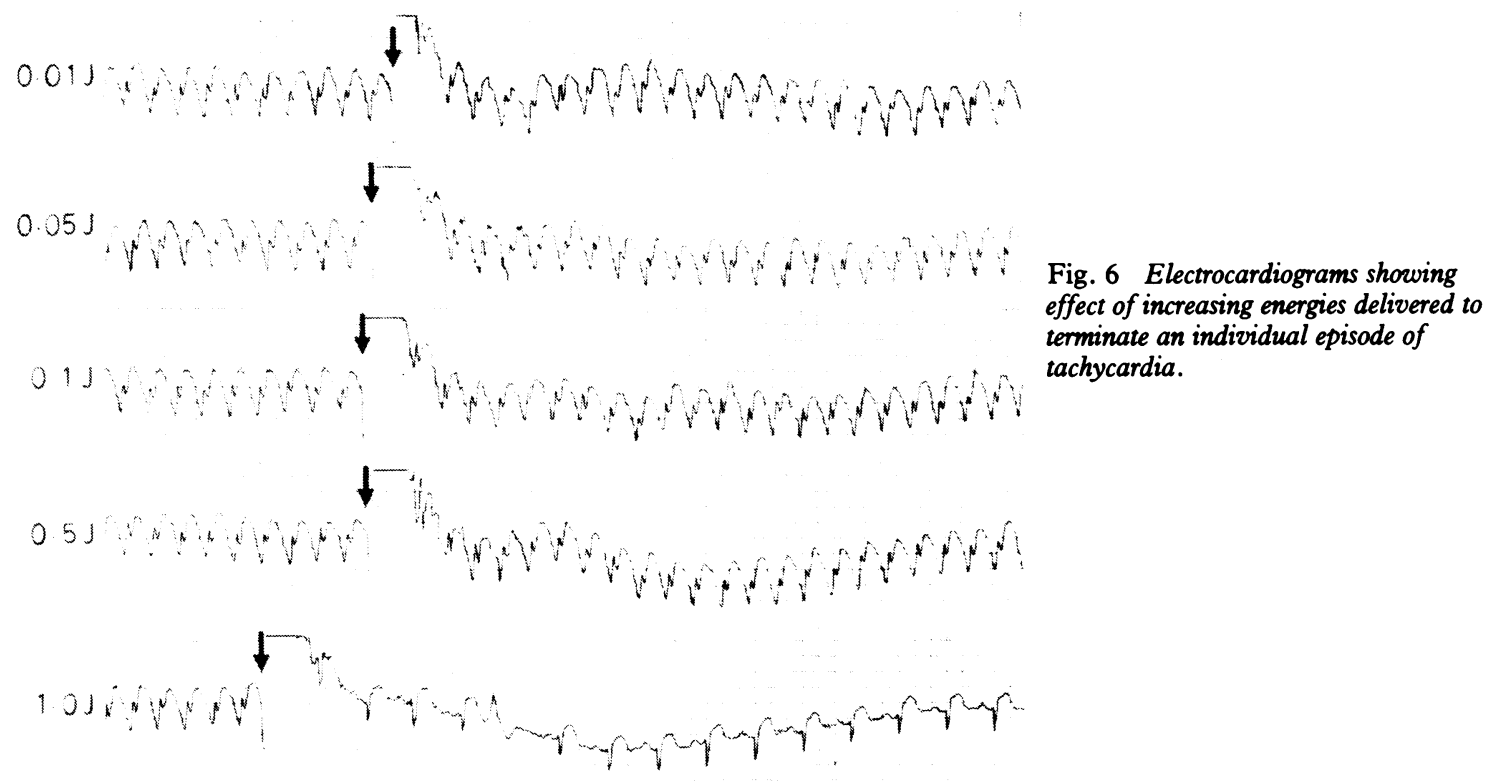

Fig. 6 Electrocardiograms showing effect of increasing energies delivered to cerminate an individual episode of tachycardia. 
could not be tried. In one patient with spontaneous ventricular tachycardia associated with syncope transvenous cardioversion failed at six energy levels $(0.05-2.0 \mathrm{~J})$; subsequent conventional transthoracic direct current cardioversion also failed, the rhythm degenerated into ventricular fibrillation, and the patient died. Necropsy showed severe three vessel coronary artery disease and a dilated left ventricle. Detailed examination of the right ventricular apex, where the discharges had been delivered, failed to show any significant pathological changes caused by the shocks. Thus in four of the five cases in which discharges failed the energy used was probably inadequate.

In no case did the tachycardia accelerate or degenerate into ventricular fibrillation, although in one case successful termination was followed by three repetitive ventricular complexes and a brief run of atrial fibrillation; sinus rhythm spontaneously returned after 30 seconds. In seven instances subthreshold discharges advanced the next ventricular electrogram $(10-20 \mathrm{~ms})$ without accelerating the tachycardia. This brief change in cycle length was unrelated to the energy delivered.

\section{PATIENT REACTION}

Eight of the nine patients were fully conscious at the time of cardioversion. Six patients experienced either moderate or severe discomfort while the remaining two felt only minor discomfort. In most patients there appeared to be no relation between the energy used and the degree of discomfort experienced. Typically, the discharges were felt in the chest, although in one patient it was felt in the upper abdomen. The shocks were likened either to a "kick in the chest" or a "heavy hiccup." Five of the eight patients who remained conscious required multiple discharges at increasing energy levels. Three felt increasing pain with the rising energy level whereas in the other two the level of discomfort was similar. One of these described the third discharge, with the highest energy $(1.0 \mathrm{~J})$, as the "easiest," possibly because this resulted in a return to sinus rhythm.

On three of the four occasions on which the lowest energy available was delivered $(0.01 \mathrm{~J})$ the discharges caused severe pain, which in one patient was associated with involuntary hip flexion. In this patient the lead tip was repositioned against the anterior wall in the body of the right ventricle, but a second discharge of the same strength also caused pain. A second patient also experienced voluntary hip flexion, although on this occasion with a discharge of $0.5 \mathrm{~J}$. There was no obvious difference in the position of the lead in these two patients nor did pacing produce phrenic nerve stimulation.

No pronounced involuntary movements were noted in the patient who remained semiconscious.

\section{Discussion}

Antiarrhythmic drugs are the standard agents used to control recurrent ventricular tachycardia, but whether they prolong life is debatable. ${ }^{5}$ Electrical methods now offer an alternative approach. Reid et al have developed an automatic implantable defibrillator, with which ventricular fibrillation and ventricular tachycardia can be recognised6; it then responds by delivering a standard discharge of $25 \mathrm{~J}$. Much lower energies $(0.25-2.0 \mathrm{~J})$, however, are also capable of terminating a high proportion of episodes of ventricular tachycardia. ${ }^{7}$

The clinical use of low energies $(0.25-2.0 \mathrm{~J})$ for the termination of recurrent ventricular tachyarrhythmias was first reported by Zipes et al . ${ }^{2}$ The energy source was an external defibrillator in which the output had been attenuated. The technique was successful in five of seven patients; in three the cardioversion threshold was $\leqslant 0.25 \mathrm{~J}$. Forty two of the 47 successful discharges were delivered to patients who were concurrently receiving antiarrhythmic drugs, but the one episode of induced acceleration also occurred in a patient receiving antiarrhythmic medication. Waspe et al compared low energy transvenous countershock with pacing for the termination of ventricular tachycardia ${ }^{8}$; they found no significant difference in their success rates, but seven of 50 episodes were accelerated by synchronised transvenous countershock, a phenomenon that they did not observe with pacing. Their results support the observations that successful termination can be correlated with a longer cycle length of the ventricular tachycardia, ${ }^{7}$ while others have shown that acceleration is more likely with ventricular tachycardias of short cycle length $(<200 \mathrm{~ms}) .^{7}$

In our study 10 of $15(75 \%)$ episodes of ventricular tachycardia were successfully terminated; the mean threshold for termination was $\mathbf{0 . 6 7} \mathrm{J}$. In four of the five failures we were prevented from using higher energies because of discomfort associated with the discharges or because of spontaneous termination. Although the numbers are small our data suggest an inverse relation between the threshold for termination and the cycle length of the ventricular tachycardia.

Jackman and Zipes have shown that the timing of the discharge within the QRS complex is important. 7 Discharges occurring within the first $80 \%$ of the QRS complex rarely caused even repetitive ventricular responses, while discharges in the terminal $20 \%$ of the QRS complex easily induced acceleration or degeneration. With a fully automatic implantable cardioverter the apical right ventricular electrogram could be used both to sense the ventricular tachycardia and to synchronise the delivery of the cardioverting discharge. 
Our study examined the relation of timing of sensing, taken from the apical right ventricular electrogram, to the onset of the QRS complex and to the origin of the ventricular tachycardia. We found that the delay of sensing from the onset of the QRS complex was significantly greater in those episodes arising from the left ventricle than in those arising from the right ventricle and that this delay was due to the apical right ventricular electrogram occurring later in the QRS complex. But in the majority of cases in our study sensing occurred within the first $80 \%$ of the QRS complex; in only one case was it later (QS/QRS 83\%).

Because the synchronisation of sensing and of discharge to the QRS complex is crucial to the safety of this technique it is important to establish that sensing falls within the first $80 \%$ of the QRS complex during tachycardia. The possibility of poor synchronisation caused by a delayed right ventricular electrogram is most likely when there is local slowed conduction at the right ventricular apex, such as may be seen in right ventricular dysplasia or possibly under the influence of antiarrhythmic drugs.

We have also noted that discharges could theoretically be delivered outside the QRS complex when the cycle length of the ventricular tachycardia is shorter than the refractory period of the unit. Modifications made to the blanking circuit of the cardioverter are likely to prevent such malsensing, but the unit may then possibly fail to respond to rapid tachycardias.

Previous reports ${ }^{238}$ suggested that transvenous cardioversion is well tolerated, especially if the energy used can be kept below $0.5 \mathrm{~J}$; if higher energies are needed sedation may be required. In our experience, however, low energy settings (for example, $0.01 \mathrm{~J}$ ) are equally likely to cause severe discomfort, although patients who had received previous transthoracic cardioversion while still conscious found transvenous discharges more tolerable. Radical modifications to the cathode, such as the use of an epicardial patch, may profoundly reduce the energy required for termination of ventricular tachycardia ${ }^{7}$ and allow energies to be used which may not cause discomfort but at the cost of a more extensive procedure.

There is scope for an external manually operated model, as we have used, connected to an intracardiac lead in the coronary care unit or catheter laboratory as an alternative to repeated conventional external direct current cardioversion, especially as having an electrode in situ would be useful for electrophysiological assessment or pacing, although Yee et al have recorded that the pacing threshold may rise immediately after conversion. ${ }^{9}$

Our findings show that synchronisation taken from the right ventricular apical electrogram is adequate to ensure that a cardioverting discharge will be delivered within the QRS complex, the majority occurring within the first $80 \%$. Such synchronisation cannot, however, be assumed and the relation of the apical right ventricular electrogram to the $Q R S$ complex during ventricular tachycardia should be carefully examined, especially in patients in whom the right ventricular apical electrogram might be delayed. The discomfort experienced by the conscious patient remains a major drawback. Although we saw no episodes of acceleration or degeneration, other studies have indicated this possibility. ${ }^{8} \mathrm{~A}$ unit with which it is possible to recognise and differentiate between ventricular tachycardia and fibrillation could obviate this problem. It would be possible to select the energy delivered appropriate to the arrhythmia and offer back up automatic defibrillation should ventricular tachycardia accelerate. Using lower energies to terminate ventricular tachycardia would prolong the effective life of the energy source.

\section{References}

1 Zipes DP, Jackman WM, Heger JJ, et al. Clinical transvenous cardioversion of recurrent life-threatening ventricular tachyarrhythmias: low energy synchronized cardioversion of ventricular tachycardia and termination of ventricular fibrillation in patients using a catheter electrode. Am Heart f 1982; 103: 789-94.

2 Yee R, Zipes DP, Gulamhusein S, Kallok MJ, Klein GJ. Low energy countershock using an intravascular catheter in an acute cardiac care setting. Am $\mathcal{F}$ Cardiol 1982; 50: 1124-9.

3 Kallok MJ, Fisher JD, Fletcher RD, et al. Intracavitary cardioversion and defibrillation-a multicenter study [Abstract]. Circulation 1983; 68 (suppl III): 89.

4 Fontaine G, Guiraudon G, Frank R, et al. Stimulation studies and epicardial mapping in ventricular tachycardia; study of mechanisms and selection for surgery. In: Kulbertus HE, ed. Reentrant arrhythmias: mechanisms and treatment. Lancaster: MTP, 1977: 334-50.

5 Swerdlow CD, Winkle RA, Mason JW. Determinants of survival in patients with ventricular tachycardia. $N$ Engl f Med 1983; 308: 1436-42.

6 Reid PR, Mirowski M, Mower MM, et al. Clinical evaluation of the internal automatic cardioverter-defibrillator in survivors of sudden cardiac death. Am f Cardiol 1983; 51: 1608-13.

7 Jackman WM, Zipes DP. Low-energy synchronous cardioversion of ventricular tachycardia using a catheter electrode in a canine model of subacute myocardial infarction. Circulation 1982; 66: 187-95.

8 Waspe LE, Kim SG, Matos JA, Fisher JD. Role of a catheter lead system for transvenous countershock and pacing during electrophysiologic tests: an assessment of the usefulness of catheter shocks for terminating ventricular tachyarrhythmias. Am F Cardiol 1983; 52: 47784.

9 Yee R, Jones DL, Klein GJ. Pacing threshold changes after transvenous catheter countershock in man [Abstract]. $\mathcal{F}$ Am Coll Cardiol 1984; 3: 554. 